\title{
Oficinas de linguagem: proposta de atendimento psicopedagógico para crianças com queixas escolares ${ }^{1}$
}

\author{
Luciana Carla dos Santos Elias \\ Edna Maria Marturano \\ Universidade de São Paulo - Ribeirão Preto
}

\begin{abstract}
Resumo
Quando o baixo rendimento escolar está associado a problemas de comportamento, há risco de desajustamento psicossocial. O objetivo do estudo foi verificar os efeitos de uma intervenção baseada em princípios da aprendizagem mediada, sobre o desempenho acadêmico e problemas de comportamento, em crianças que apresentam ambas as dificuldades. Participaram do estudo 17 meninos, com idade entre sete e onze anos, encaminhados a uma clínica de psicologia por dificuldades escolares. As dificuldades acadêmicas e comportamentais das crianças foram avaliadas antes e após a intervenção, tendo como informantes as crianças e suas mães. A intervenção consistiu de 20 oficinas de linguagem, realizadas semanalmente em pequenos grupos. Após a intervenção, verificaram-se progressos no desempenho escolar e atenuação dos problemas de comportamento. Problemas de atenção e manifestações internalizantes parecem sensíveis à intervenção, ao passo que comportamentos agressivos tendem a persistir. Estudos de seguimento são necessários para verificar a permanência dos efeitos encontrados.
\end{abstract}

Palavras-chave: apoio psicopedagógico; desempenho escolar; problemas de comportamento; avaliação de intervenção

\begin{abstract}
Language workshops: a psycho-educational intervention for children presenting academic complaints. The association between school underachievement and behavior problems is a risk factor for psychosocial disturbance. The aim of this study was to verify the effects of an intervention based on mediated learning principles to reduce academic and behavior problems in children presenting both difficulties. The study sample was composed by 17 boys, aged 7 to 11 years. All of them were referred to a child guidance clinic due to school underachievement. Academic and behavioral difficulties were assessed before and after intervention, by means of data provided by children themselves and their mothers. Intervention consisted of 20 weekly small-group language workshops. After intervention, there have been gains in academic achievement and a decrease in behavior problems. Attention and internalizing problems seem to be more affected by intervention, while aggressive behavior tends to persist at pre-intervention levels. Follow-up studies are required to assess the lasting effects of the intervention.
\end{abstract}

Keywords: psycho-educational support; school achievement; behavior problems; intervention assessment

$\mathrm{U}$ ma parcela apreciável da demanda das clínicas de psicologia é constituída por famílias que buscam ajuda profissional para as dificuldades escolares de seus filhos. Trata-se em geral de crianças na faixa dos sete aos 12 anos, cursando as séries iniciais do ensino fundamental, havendo predomínio de meninos em razão que pode chegar a 4:1 (Barbosa \& Silvares, 1994; Elias, 2002; Santos, 1990). Essas famílias freqüentemente trazem sentimentos de angústia, perplexidade e impotência.

Esse quadro de inquietação familiar configura, para a criança afetada, uma vivência de fracasso. A chegada à clínica constitui um marco nesse processo, ao simbolizar o momento crítico em que esses indivíduos recebem uma chancela social de incompetência frente àquela que é considerada, em nossa cultura, como uma das principais tarefas evolutivas da fase escolar - a produtividade (Erikson, 1971; Masten \& Coastworth, 1998). Assim, quando a criança que vai mal na escola chega ao profissional de saúde, conduzida pela família, uma crise está instalada. São sugestivas de um quadro de crise as manifestações sócio-emocionais encontradas em uma elevada porcentagem de crianças por ocasião da busca de atendimento (Elias, 2002). Algumas dessas manifestações, como queixas somáticas e dificuldades de concentração, caracterizam-se mesmo como sintomas de stress infantil (Lipp \& Romano, 1987). 


\section{Indicadores de vulnerabilidade em crianças com queixas escolares}

De acordo com a percepção dos professores, esses alunos apresentam mais dificuldades de adaptação às demandas da sala de aula, quando comparados aos colegas com rendimento satisfatório. Sua abordagem da tarefa escolar é impulsiva, desatenta e confusa, denotando ainda desinteresse, retraimento e não persistência. Nos relacionamentos interpessoais, a desvantagem se verifica também em comparação aos alunos que estão apresentando um rendimento pobre, mas não foram encaminhados para atendimento psicológico: frente à professora, mostram-se mais dependentes, rebeldes e tensos; no relacionamento com os colegas, são considerados mais provocativos, agressivos, desrespeitosos, individualistas, intolerantes e explosivos. No ambiente familiar, as mães relatam características de impulsividade, humor depressivo e dificuldades interpessoais. O funcionamento sócio-emocional se caracteriza por controle pobre dos impulsos, dependência e certa desorganização da conduta, como se a criança estivesse lidando com situações que excedem seus recursos de enfrentamento (Marturano, Loureiro, Linhares, \& Machado, 1997). Há evidência de que as dificuldades tentem a persistir na adolescência, particularmente quando há problemas nas relações interpessoais (Campos \& Marturano, 2003).

No plano subjetivo, as crianças com queixas escolares apresentam auto-imagem negativa, com intensos sentimentos de inferioridade e menos valia, relacionados a vivências depressivas (Jacob, 1997). Seu auto-conceito é menos favorável e elas têm um baixo senso de auto-eficácia quando comparadas a crianças com bom rendimento acadêmico (Jacob, 2001).

O quadro esboçado é sugestivo de que muitas dessas crianças vivem um momento de vulnerabilidade, requerendo ações de saúde mental, seja para alívio do sofrimento psíquico de que dão mostras, seja para suporte ao enfrentamento da crise, seja para a prevenção de maiores dificuldades futuras.

\section{As Oficinas de Linguagem}

As Oficinas de Linguagem, sistematizadas em uma clínica de psicologia vinculada ao SUS, constituem modalidade de intervenção para essa clientela, tendo por meta ajudar as crianças a desenvolver um positivo senso de auto-eficácia para tarefas escolares e uma disposição afetiva favorável em relação ao aprendizado de leitura e escrita.

Fundamentos. As oficinas de linguagem se baseiam no pressuposto de que a cognição faz a ponte entre a experiência prévia do indivíduo e seus comportamentos atuais, ou seja, as representações mentais da experiência são o veículo através do qual a experiência anterior influencia novas situações (Hughes, 2000). Com base no pressuposto do papel mediador da cognição, espera-se que o senso de competência das crianças seja fortalecido por experiências concretas de sucesso em situações de aprendizagem e possa, por sua vez, influir positivamente em seu sucesso futuro. As oficinas de linguagem possibilitam tais experiências, ao propor mini-situações de experiência de aprendizagem mediada em pequenos grupos.
A experiência de aprendizagem mediada é aquela que promove modificabilidade cognitiva e flexibilidade do comportamento, através de interações entre o aprendiz e um mediador que ativamente processa os estímulos aos quais aquele é exposto (Goulart, Guhur, \& Mori, 2001). Para a intervenção em oficinas de linguagem, são de particular importância os critérios de experiência de aprendizagem mediada detalhados por Linhares (1998) e Goulart, Guhur e Mori (2001): (a) intencionalidade e reciprocidade - há a intenção de transmitir uma mensagem e compartilhar esta intencionalidade com o aprendiz, ou seja, este interage com o material apresentado pelo mediador; (b) significado - o mediador deve mostrar o sentido de aprender algo, estabelecer com a criança o significado afetivo, cultural ou social da tarefa proposta; (c) transcendência - a mediação deve transcender à situação específica, extraindo princípios e informações que podem ser úteis em outras situações; (d) competência deve-se comunicar à criança de diversas formas que ela é capaz de funcionar de maneira independente e bem-sucedida e organizar oportunidades para que isso ocorra; (f) autoregulação - cabe ao mediador assistir o aprendiz na regulação de características impulsivas ou inibidas, bem como de seu ritmo, conforme as demandas da situação.

Os três primeiros critérios são tidos como universais, por assegurarem a modificabilidade e a flexibilidade (Goulart, Guhur, \& Mori, 2001). Os dois últimos são fundamentais para as oficinas, dadas as características psicológicas da clientela-alvo, que incluem baixo senso de eficácia e auto-regulação pobre.

A aprendizagem é, assim, vista nas oficinas como construção conjunta, e a mediação da aprendizagem é entendida como um processo de interação entre uma pessoa em desenvolvimento e a outra, no caso, um adulto experiente, que, de forma intencional, seleciona e organiza experiências de aprendizagem (Linhares, 1998).

Enquadre. A indicação para participação em oficinas de linguagem é feita por psicólogo da clínica, após avaliação da criança. É feito um contrato verbal com a família, para um período de 18 a 22 semanas, com início em março ou agosto, coincidindo com o início do semestre letivo na escola. Um contrato pode ser renovado por igual período mediante consenso, caso se verifique a persistência de dificuldades que a freqüência às oficinas pode ajudar a superar. $\mathrm{O}$ atendimento é feito em pequenos grupos, com três a cinco crianças do mesmo sexo, e inclui encontros semanais com duração de uma hora e meia a duas horas.

As sessões são estruturadas em torno de tarefas coletivas, como pesquisas e projetos; a linguagem oral e escrita é usada ativamente como meio para alcançar os objetivos comuns. O profissional coordenador dos grupos tem uma importante função mediadora, mediante assistência às crianças nas zonas de desenvolvimento proximal, de acordo com os critérios explicitados acima, na seção relativa a fundamentos.

As duas sessões iniciais são dedicadas à familiarização entre os membros do grupo, proposição de metas comuns, sondagem dos interesses dos participantes e elaboração con- 
junta de regras para o funcionamento do grupo, bem como de conseqüências para a transgressão das regras. Da terceira sessão em diante, as crianças desenvolvem pesquisas e projetos coletivos sobre temas de interesse do grupo. Os recursos usados para essas atividades incluem uma variedade de fontes como livros de história, enciclopédias, revistas, jornais, mapas e fotos. $\mathrm{O}$ adulto mediador oferece diretrizes para a atividade e assistência em cada etapa do trabalho. As pesquisas incluem em geral as seguintes etapas: escolha do tema; consulta às fontes de informação acessíveis e registro das mesmas; elaboração de um sumário escrito. Em cada etapa, as tarefas são divididas e ajustadas às capacidades individuais. Quando o grupo decide desenvolver um projeto sobre o tema pesquisado, as etapas são: definição do objetivo (informar, divertir, persuadir, etc.) e do produto (um livro, um cartaz, um jogo de regras, uma maquete, etc.); planejamento; listagem dos materiais necessários; divisão das tarefas entre os membros do grupo; execução das tarefas; verificação do produto final e retificação, quando necessário. Toda atividade escrita no projeto é planejada como uma operação de três fases: préescrita ou rascunho, revisão e escrita definitiva. O produto final de todo projeto fica exposto no saguão de entrada da clínica durante pelo menos dez dias. As produções de cada criança nas diferentes etapas das pesquisas e projetos - anotações, rascunhos, esboços, desenhos - são arquivadas em pastas individuais.

A estrutura básica de uma sessão de oficina inclui quatro a cinco partes. Nos dez minutos iniciais de cada sessão as crianças e o mediador se sentam ao redor da mesa de trabalho e as crianças são encorajadas a falar sobre sua última semana e a participar dos diálogos em torno dos assuntos trazidos pelos outros membros do grupo. Os 60 a 90 minutos subseqüentes são dedicados às atividades de pesquisa ou projeto planejadas pelo grupo na sessão anterior. Instrução individualizada em habilidades de leitura e escrita é proporcionada quando necessário, tomando aproximadamente 15 minutos. Em seguida, as crianças escolhem um jogo de regras e jogam uma ou duas partidas. No fechamento da oficina, cada criança é encorajada a expressar sua opinião sobre as atividades e a refletir sobre seu comportamento e o funcionamento do grupo; em seguida, o mediador faz uma síntese da sessão em seus aspectos operativos e interpessoais, pontuando os desafios surgidos, as soluções encontradas, os ganhos de aprendizagem e as contribuições de cada participante para o cumprimento das tarefas que o grupo havia planejado para aquele encontro.

Na última sessão o mediador retoma os objetivos iniciais, mencionando e mostrando concretamente os progressos alcançados por cada criança, através do manuseio da pasta de produções individuais e recapitulação das produções coletivas.

Diretrizes para a condução do processo são fornecidas no Manual do mediador das oficinas de linguagem, com base nas propostas de Fonseca (1995) e Mentis (1997). Tratase de diretrizes gerais, visto que o processo é essencialmente interativo e as atividades são desenvolvidas de acordo com as características de cada grupo. O manual inclui também ins- truções sobre manejo de comportamentos em situação de grupo e modalidades específicas de comunicação e apoio sugeridas por Kernberg e Chazan (1993).

\section{As oficinas de linguagem e os problemas sócio- emocionais de crianças com dificuldades escolares}

Como intervenção de baixa periodicidade - uma vez por semana -, as oficinas de linguagem não propiciam recuperação do desempenho escolar ao nível da série (Clay, 1993). Espera-se, entretanto, que esta experiência de aprendizagem mediada proporcione à criança maior flexibilidade para aproveitamento de novas experiências de aprendizagem, avançando assim na zona de desenvolvimento proximal.

Além disso, tendo sido concebidas de modo a fortalecer o senso de competência da criança, pode-se supor que as oficinas de linguagem terão efeito positivo de redução de tensões emocionais e problemas de comportamento, comuns em crianças com dificuldades acadêmicas.

Na investigação relatada neste artigo, as oficinas de linguagem foram avaliadas quanto a seus efeitos sobre o desempenho acadêmico e os problemas sócio-emocionais de meninos referidos para atendimento em razão do desempenho escolar pobre. Especificamente, visou-se comparar medidas de desempenho e de problemas de comportamento das crianças antes e após a intervenção psicopedagógica. A amostra foi constituída de meninos, dada a predominância do gênero masculino na população referida às clínicas de psicologia por dificuldades escolares.

\section{Método}

O estudo foi realizado em uma clínica-escola de Psicologia vinculada à rede SUS de atendimento, em uma cidade de aproximadamente 500 mil habitantes no interior do Estado de São Paulo.

\section{Participantes}

Participaram do estudo 17 meninos, com idades entre sete e 11 anos, cursando entre a $1^{\underline{a}}$ e a $4^{\underline{a}}$ séries, e suas respectivas mães ou responsáveis. Todos estavam inscritos na clínica, tendo como queixa primária o baixo rendimento escolar, e aguardavam atendimento.

Os participantes foram selecionados de acordo com os seguintes critérios: (a) não apresentar indício de déficit cognitivo em teste de inteligência; (b) ser capaz de ler e escrever palavras formadas por sílabas simples, de estrutura consoante-vogal, em teste de desempenho escolar; e (c) apresentar problemas de comportamento com pontuação acima de 16 na Escala Comportamental Infantil de Rutter, como indicativo de necessidade de ajuda psicológica na visão dos pais (Graminha \& Coelho, 1994).

\section{Instrumentos}

Os instrumentos utilizados foram: Teste das Matrizes Progressivas Coloridas de Raven (Angelini, Alves, Custódio, \& Duarte, 1997), para triagem de participantes com de- 
sempenho acima do percentil 5, de modo a atender ao critério de ausência de déficit cognitivo; Teste de Desempenho Escolar - TDE (Stein,1994); um formulário com cinco questões fechadas para investigação de dificuldades na lição de casa, empregado rotineiramente na clínica; Escala Comportamental Infantil A2 de Rutter - ECI (Graminha 1998); Inventário de Comportamentos da Infância e Adolescência - CBCL (Achenbach, 1991; Bordin, Mari, \& Caeiro, 1995).

\section{Procedimento de Coleta}

A avaliação pré-intervenção ocorreu durante a entrevista de triagem clínica do serviço onde se realizou o estudo. Por carta ou telefonema, as mães de crianças inscritas que aguardavam atendimento eram convidadas a comparecer com seu filho, em dia e horário marcado. As entrevistas com a mãe e a criança ocorriam simultaneamente, realizadas pela primeira autora e uma auxiliar de pesquisa, ambas psicólogas. Todos os instrumentos eram aplicados em uma única sessão. A criança respondia ao Raven e ao TDE. Na entrevista com a mãe eram aplicados a ECI, o CBCL e o formulário sobre a lição de casa. Mediante os resultados dessa avaliação, as mães das crianças que preenchiam os critérios de inclusão na pesquisa eram consultadas e, caso concordassem, assinavam o Termo de Consentimento Livre e Esclarecido. Na prática, todas as mães consultadas assentiram em participar da pesquisa. As crianças que não preenchiam os critérios eram encaminhadas para atendimento com outros profissionais na própria clínica. Quando necessário, eram feitos encaminhamentos para outros serviços.

Foram constituídos seis grupos de intervenção em oficinas de linguagem, com três a cinco membros. Respeitado o horário escolar das crianças, buscou-se formar grupos homogêneos quanto ao desempenho em leitura e escrita.

As crianças passaram por intervenção durante 20 sessões semanais com duração de duas horas, perfazendo carga horária total de 40 horas. A intervenção sempre tinha seu início coincidindo com o início de um semestre letivo. De acordo com norma da clínica onde o trabalho foi desenvolvido, as mães recebiam orientação quinzenal em grupo. Trabalhavam-se com as mães questões focais sobre manejo das dificuldades acadêmicas e sócio-emocionais. As orientações duravam de uma a uma hora e meia, perfazendo carga horária total de 10 a 15 horas.

Após o término da intervenção, as crianças eram reavaliadas, utilizando-se os mesmos instrumentos e procedimentos utilizados na avaliação inicial, com exceção do Raven.

Os atendimentos foram conduzidos pela primeira autora e pela auxiliar de pesquisa, que receberam treinamento prévio para condução de oficinas de linguagem, na própria clinica onde a pesquisa foi desenvolvida.

\section{Procedimento de análise dos dados}

Os protocolos foram cotados segundo as proposições de cada técnica. Para comparação entre os escores obtidos nos dois momentos de avaliação, foram empregados três testes estatísticos, de acordo com as características métricas dos escores: teste $t$ para amostras emparelhadas, teste do Sinal e teste de Wilcoxon.

\section{Aspectos éticos}

O projeto teve a aprovação do Comitê de Ética em Pesquisa da instituição onde foi realizado. $\mathrm{O}$ convite às mães seguiu a ordem cronológica das inscrições na clínica. Todas as crianças avaliadas tiveram garantia de atendimento, segundo suas necessidades, independentemente do consentimento das mães em participar da pesquisa e de acordo com as normas do serviço. Após a conclusão do estudo, o compromisso de atendimento foi mantido e passou a ser feito por profissionais vinculados à clínica, sem solução de continuidade.

\section{Resultados}

Os resultados são apresentados em duas seções. Na primeira, mostram-se as comparações entre escores obtidos na avaliação pré-intervenção e na avaliação pós-intervenção. Na segunda, é feita a análise do significado clínico das diferenças encontradas.

\section{Comparação entre as avaliações pré e pós- intervenção}

Na Tabela 1 são apresentados os resultados relativos ao desempenho em escrita, aritmética, leitura e total, obtidos através dos escores brutos no TDE, nos dois momentos de avaliação.

Tabela 1

Médias e desvios-padrão dos escores brutos no TDE, antes e depois da intervenção

\begin{tabular}{lrrrrr}
\hline \multirow{2}{*}{ Variáveis } & \multicolumn{2}{c}{ Pré } & \multicolumn{2}{c}{ Pós } & \multirow{2}{*}{$t$} \\
\cline { 2 - 5 } & Média & $D P$ & Média & \multicolumn{1}{c}{$D P$} & \\
\hline Escrita & 16,82 & 8,08 & 19,29 & 5,19 & $-1,91 \dagger$ \\
Aritmética & 11,23 & 5,34 & 14,18 & 5,38 & $-2,64 *$ \\
Leitura & 49,12 & 18,98 & 53,29 & 18,22 & $-2,96 * *$ \\
\hline Total & 77,47 & 29,03 & 86,76 & 23,94 & $-4,07 * * *$ \\
\hline$* p<0,05 ; * *$ & $p<0,01 ; * * * p=0,001 ; \dagger p<0,10$
\end{tabular}

Os resultados da Tabela 1 indicam melhoras significativas após a intervenção, nos indicadores de leitura e aritmética, bem como no escore total do TDE. Há tendência a melhora também no escore de escrita.

Os resultados relativos a dificuldades na lição de casa são apresentados na Tabela 2, que mostra o número de participantes com dificuldades em cada momento da avaliação.

Dos 17 meninos que participaram do estudo, 14 apresentavam dificuldade na lição de casa, segundo a avaliação das mães, antes da intervenção. A dificuldade mais freqüente era a falta de iniciativa para fazer a lição. Mais de dois terços das crianças não conseguiam fazer a lição de forma independente. Após a intervenção, houve redução significativa no número de crianças com dificuldades, verificando-se melhora 
quanto à independência e à iniciativa. As poucas crianças que se recusavam a fazer a tarefa de casa deixaram de mostrar essa reação.

Os escores de problema de comportamento fornecido pela ECI também diminuíram após a intervenção. A média da amostra caiu de 26,06 ( $D P=8,64)$ para 19,35 ( $D P=9,68)$, uma variação significativa $(t=5,02 ; p<0,0001)$. Tendência semelhante foi observada em relação ao CBCL. Nas Tabelas 3 e 4, os resultados relativos ao CBCL estão expressos em escores T, que são escores normalizados (Achenbach, 1991; Bordin, Mari, \& Caeiro, 1995). A Tabela 3 apresenta as médias dos escores $\mathrm{T}$ nas oito síndromes avaliadas pelo inventário e a Tabela 4, as médias nas escalas Internalização, Externalização e Total. A escala Internalização inclui as síndromes Retraimento, Complicações Somáticas e Ansiedade / Depressão, ao passo que a escala Externalização inclui as síndromes Comportamento Delinqüente e Comportamento Agressivo.

As médias pré-intervenção apresentadas na Tabela 3 indicam que os problemas de comportamento com médias mais altas antes da intervenção eram: problemas de atenção ("não consegue se concentrar, é irrequieto, é muito excitado ou tenso"); comportamento agressivo ("é mal humorado, exige muita atenção, é desobediente em casa”); problemas sociais ("age de maneira infantil para sua idade, é muito dependente”); e retraimento ("aborrece-se com facilidade, guarda as coisas para si mesmo”). Com exceção dos problemas de atenção, os demais refletem dificuldades interpessoais.
Das três síndromes do CBCL em que houve melhora significativa após as oficinas, duas se encontravam no rol de problemas com maiores médias pré-intervenção. Comportamento delinqüente e problemas sociais tiveram as mudanças mais significativas. Houve melhoras também nos problemas de atenção; os sintomas de ansiedade e depressão tendem a diminuir.

Tendência semelhante de diminuição dos problemas de comportamento aparece nos resultados da Tabela 4. Os participantes obtiveram melhoras significativas no indicador de problemas internalizantes e tendência à melhora em problemas externalizantes. A diferença mais acentuada foi no escore total do CBCL, que inclui as escalas acima e mais 65 itens. Esse resultado denota uma redução generalizada de problemas comportamentais.

\section{Significado clínico das melhoras obtidas}

Considerando que os participantes do estudo eram clientes de uma clínica de psicologia, com problemas de comportamento associados ao desempenho escolar pobre, foi feita a análise do significado clínico das mudanças encontradas após a intervenção. Essa análise incluiu apenas os dados de instrumentos que forneciam normas ou pontos de corte para diferenciar problemas em nível clínico ou desempenho inferior ao esperado. Na Tabela 5 está indicado o número de participantes com status clínico em cada instrumento, antes e depois da intervenção.

Tabela 2

Número de crianças com dificuldades na lição de casa antes e depois da intervenção e probabilidades associadas às diferenças entre os dois momentos

\begin{tabular}{lrrc}
\hline \multicolumn{1}{c}{ Variáveis } & Pré & Pós & $p$ \\
\hline Freqüentemente tem dificuldade na lição de casa & 14 & 5 & $0,01^{*}$ \\
Não toma iniciativa para fazer a lição & 14 & 5 & $0,004^{* *}$ \\
Não consegue fazer a lição sem ajuda & 11 & 2 & $0,004^{* *}$ \\
Faz muitas interrupções durante a realização da tarefa & 8 & 4 & n. s.** \\
Recusa-se a fazer a lição & 4 & 0 & n. s.** \\
\hline
\end{tabular}

* Teste Wilcoxon; ** Teste do Sinal

Tabela 3

Médias e desvios-padrão dos escores $T$ nas síndromes do CBCL, antes e depois da intervenção

\begin{tabular}{lrrrrl}
\hline \multirow{2}{*}{\multicolumn{1}{c}{ Variáveis }} & \multicolumn{2}{c}{ Pré } & \multicolumn{2}{c}{ Pós } \\
\cline { 2 - 5 } & Média & \multicolumn{1}{c}{$D P$} & Média & DP & \\
\hline Retraimento & 62,82 & 10,57 & 61,41 & 9,45 & 0,83 \\
Complicações somáticas & 60,41 & 9,03 & 57,47 & 6,73 & 1,19 \\
Ansiedade e depressão & 60,59 & 8,59 & 57,35 & 10,58 & $1,94 \dagger$ \\
Problemas sociais & 64,76 & 10,13 & 57,17 & 6,52 & $3,87 * * *$ \\
Problemas de pensamento & 58,18 & 9,19 & 56,35 & 9,22 & 0,75 \\
Problemas de atenção & 72,47 & 10,55 & 67,12 & 10,27 & $2,52 *$ \\
Comportamento delinqüente & 59,00 & 8,32 & 54,76 & 6,76 & $2,96 * *$ \\
Comportamento agressivo & 66,23 & 14,86 & 62,94 & 10,57 & 1,56 \\
\hline
\end{tabular}

* $p<0,05 ; * * p<0,01 ; * * * p<0,001 ; \dagger p<0,10$ 
Tabela 4

Médias e desvios-padrão dos escores $T$ de problemas de comportamento nas escalas do CBCL: Internalização, Externalização e Total, antes e depois da intervenção

\begin{tabular}{crrrrr}
\hline \multirow{2}{*}{ Variáveis } & \multicolumn{2}{c}{ Pré } & \multicolumn{2}{c}{ Pós } & \multirow{2}{*}{$t$} \\
\cline { 2 - 5 } & Média & \multicolumn{1}{c}{$D P$} & Média & \multicolumn{1}{c}{$D P$} & \\
\hline Internalização & 63,35 & 9,50 & 58,18 & 11,93 & $2,71^{*}$ \\
Externalização & 62,23 & 11,96 & 59,71 & 10,17 & $1,78 \dagger$ \\
\hline Total & 65,41 & 9,37 & 60,94 & 9,74 & $4,23 * * *$ \\
\hline
\end{tabular}

${ }^{*} p<0,05 ; * * p<0,01 ; * * * p<0,001 ; \dagger p<0,10$

Antes da intervenção, observa-se que 15 meninos apresentavam desempenho escolar aquém de sua série, o que é compatível com o motivo de encaminhamento para a clínica. Já quanto aos problemas de comportamento, os escores no CBCL não coincidem totalmente com o critério de pré-seleção baseado no ponto de corte da ECI. Dos 17 meninos selecionados segundo esse critério, dez foram diagnosticadas no CBCL como tendo problemas de comportamento com status clínico na Escala Total antes da intervenção. Os problemas de atenção sobressaem como a síndrome que afeta clinicamente o maior número de meninos desta amostra. As outras três síndromes que na Tabela 3 aparecem com as médias mais elevadas de escore $\mathrm{T}$ pré-intervenção, e que se referem a dificuldades interpessoais, apresentam-se em status clínico para um pequeno número de participantes. Entretanto, no conjunto, dez crianças apresentam alguma dificuldade interpessoal em nível clínico antes da intervenção.

Após a intervenção, as mudanças foram discretas, com exceção dos resultados relativos a problemas de comportamento na ECI e a problemas de atenção no CBCL, em que o número de crianças com status clínico foi reduzido quase à metade. Há variação entre as síndromes no que se refere à mudança de status clínico. Enquanto problemas de atenção, problemas sociais, complicações somáticas e comportamento delinqüente perdem status clínico, comportamento agressivo e retraimento parecem persistir nos mesmos níveis.

Conforme está indicado no rodapé da Tabela 5, houve casos de piora em alguns indicadores de problema de comportamento do CBCL. Chamam a atenção os resultados na escala Internalização, em que um participante passou do status normal ao clínico. Inspecionando-se os protocolos de avaliação deste participante, verificou-se que, antes da intervenção, apresentava escores clínicos nas escalas Externalização e Total do CBCL, assim como nas síndromes Problema de Atenção e Comportamento Agressivo. Tinha dificuldades com a lição de casa e desempenho aquém de sua série. Após a intervenção, esta criança não alterou as dificuldades anteriores com a lição de casa, nem os problemas de atenção ou os comportamentos agressivos; apresentou piora no desempenho de escrita e na síndrome Ansiedade / Depressão do CBCL. Após a reavaliação, foi encaminhada para atendimento individual. Uma avaliação de seguimento seis meses depois indicou um perfil comportamental dentro da faixa normal no CBCL e melhora no desempenho escolar, porém abaixo das normas para sua idade e série.

Tabela 5

Status clínico dos participantes antes e depois da intervenção

\begin{tabular}{|c|c|c|}
\hline \multirow{2}{*}{ Indicador } & \multicolumn{2}{|c|}{ Número de crianças } \\
\hline & Pré & Pós \\
\hline Desempenho inferior à norma do TDE para sua idade ou série & 15 & 11 \\
\hline Escore de problema de comportamento em nível clínico na ECI & 17 & 10 \\
\hline \multicolumn{3}{|l|}{ Escore $\mathrm{T}$ clínico no CBCL } \\
\hline Retraimento & 5 & 4 \\
\hline Complicações somáticas & 2 & 0 \\
\hline Ansiedade e depressão* & 2 & 2 \\
\hline Problemas sociais & 3 & 0 \\
\hline Problemas de pensamento* & 3 & 2 \\
\hline Problemas de atenção & 11 & 6 \\
\hline Comportamento delinqüente & 2 & 0 \\
\hline Comportamento agressivo* & 5 & 5 \\
\hline Internalização** & 8 & 6 \\
\hline Externalização & 7 & 6 \\
\hline Total & 10 & 8 \\
\hline
\end{tabular}

* Em um caso, os problemas passaram do status limítrofe para o clínico após a intervenção

** Em um caso, os problemas passaram do status normal para o clínico após a intervenção 


\section{Discussão}

A investigação relatada neste artigo focalizou a modalidade de apoio psicopedagógico denominada oficinas de linguagem, verificando sua eficácia para melhorar o desempenho e atenuar problemas de comportamento em meninos com queixa de desempenho escolar pobre. Antes da intervenção, as crianças incluídas no projeto apresentavam, como grupo, ausência de iniciativa e dependência de ajuda para a lição de casa, problemas de atenção, dificuldades interpessoais e elevado escore de problemas de comportamento, além do baixo desempenho escolar.

A comparação entre medidas obtidas antes e depois da intervenção sugeriu, em relação aos problemas modais da amostra, melhora no desempenho escolar, mais iniciativa e independência na lição de casa, melhora das dificuldades de atenção e diminuição dos problemas de comportamento. Outras dificuldades, menos freqüentes na amostra, pareceram também sensíveis à intervenção. Atenuaram-se os sinais de imaturidade interpessoal, os comportamentos anti-sociais e as manifestações internalizantes. Por outro lado, persistiram problemas interpessoais como retraimento e comportamento agressivo.

Um aspecto positivo desses resultados é que diversos problemas que se mostraram maleáveis à intervenção correspondem a características repetidamente encontradas nessa população clínica, tais como problemas de atenção e manifestações internalizantes (Elias, 2003; Marturano et al., 1997).

A configuração das melhoras detectadas indica com clareza que os maiores benefícios incidem sobre aspectos relevantes para o desempenho acadêmico, o que está de acordo com os objetivos da intervenção. As oficinas parecem (re)ativar processos internos facilitadores do aprendizado escolar. Após a intervenção, os participantes se mostram menos dispersos, menos dependentes de ajuda e com mais iniciativa nas tarefas. Esse conjunto de recursos das crianças, resgatados fora do contexto das sessões de oficina, denotam que após 20 semanas de atendimento elas estão mais equipadas e dispostas para tirar proveito de oportunidades de aprendizado oferecidas em outros contextos, como a sala de aula, programas de aceleração do aprendizado ou classes de recuperação. É plausível supor que as melhoras verificadas no teste de desempenho acadêmico sejam em parte decorrentes desse processo que, uma vez iniciado, tem boas chances de se manter no tempo, desde que retroalimentado nos sistemas de suporte escolar e familiar. A ação de um processo de retroalimentação que, uma vez superados os obstáculos momentâneos, sustenta e impulsiona o progresso escolar da criança, é sugerida pelos dados de Campos e Marturano (2003). Em estudo de seguimento com crianças que receberam apoio psicopedagógico para superação de suas dificuldades escolares, essas autoras verificaram que as crianças mais sociáveis, envolvidas em relações interpessoais harmoniosas, são as que mais mantêm os ganhos obtidos com o atendimento e conseguem mais progresso acadêmico. Uma orientação social positiva pode ser crucial para procurar, eliciar, perceber e aceitar o suporte dos pais, professores e colegas, estando provavelmente no cerne desse mecanismo de retroalimentação positiva.

A esse respeito, cabe lembrar que problemas de natureza interpessoal, modais na população com queixas escolares (Elias, 2003), foram detectados, em nível clínico, em mais de metade da amostra deste estudo e, no entanto, a freqüência às oficinas não contribuiu para melhoras significativas, a não ser nos indicadores de imaturidade interpessoal, que incluem conduta infantilizada e dependência emocional em relação ao adulto. Esses resultados, ao mesmo tempo em que reafirmam o papel das oficinas na promoção da independência - tanto instrumental como afetiva - da criança, delimitam seus efeitos comportamentais. Dado que algumas das dificuldades sócio-emocionais apresentadas pelas crianças com dificuldades escolares, como agitação, irrequietude, dificuldade de concentração, queixas somáticas, tristeza e angústia, têm sido tomadas como indicadores de stress infantil (Lipp \& Romano, 1987), pode-se supor que os efeitos comportamentais das oficinas refletem alívio das tensões relacionadas à situação escolar adversa. Problemas sócio-emocionais de outra origem não seriam afetados.

Com respeito aos benefícios do atendimento, algumas ressalvas devem ser feitas. Em primeiro lugar, é preciso atentar para o fato de que algumas crianças mostraram intensificação de problemas. Especificamente, em uma criança os sintomas internalizados passaram do status normal para o clínico após a intervenção. Embora os sintomas internalizados tenham decaído significativamente na amostra como um todo, denotando alívio de tensões na maioria dos participantes, o fato de que eles se intensificaram em uma criança alerta para a necessidade de cuidadoso acompanhamento caso a caso. Esse resultado isolado, se agregado aos que indicaram persistência dos problemas relativos a comportamento agressivo e retraimento, corrobora uma visão parcimoniosa dos efeitos do atendimento, delimitando seu alcance a aspectos diretamente relacionados ao problema escolar. Como ressalta Kazdin (2000), um grande número de fatores influencia os resultados de intervenções psicossociais, e uma análise da ação desses fatores transcende o escopo desta investigação.

Em segundo lugar, as mudanças no status clínico dos problemas foram em geral modestas. Uma questão que se coloca é se, e até quando, melhoras no status clínico seriam observadas caso novas avaliações fossem feitas ao longo do atendimento, para além das 20 semanas a que se restringiu este estudo. A noção de que mais é melhor, freqüentemente assumida na pesquisa contemporânea sobre efeitos de tratamentos psicossociais (Kazdin, 2000), é uma questão a ser tratada empírica e teoricamente. Pelo menos no que diz respeito ao desempenho escolar, a resposta tende a ser negativa, já que se trata de intervenção de baixa periodicidade. $\mathrm{O}$ esquema recomendado para programas de recuperação de leitura ao nível da série em crianças iniciantes é de sessões diárias (Clay, 1993). Um progresso escolar mais acelerado poderia ser atribuído a efeitos de bola de neve, como os comentados em parágrafo anterior, a partir da melhora em aspectos do funcionamento da criança que são requisitos para 
o aprendizado acadêmico e que as oficinas parecem promover, de acordo com suas finalidades.

Duas ressalvas adicionais devem ser feitas, como limites metodológicos impostos pela realização do estudo em situação real de atendimento clínico. Consoante o compromisso ético com os clientes da clínica, o delineamento adotado não incluiu um grupo não-tratado, o que seria necessário para se poder afirmar que as melhoras observadas não se devem meramente à passagem do tempo. Pode-se argumentar, a esse respeito, que por se tratar de famílias que procuram ajuda clínica para lidar com as dificuldades da criança, é pouco plausível que melhoras em múltiplos domínios do funcionamento da criança tivessem ocorrido independentemente dessa ajuda, em padrão coerente com os objetivos da intervenção.

Uma segunda limitação do delineamento é que não há como dissociar eventuais efeitos das oficinas de linguagem e das orientações às mães, que foram concomitantes. Podese supor que as melhoras se devem, pelo menos em parte, a mudanças de atitudes e comportamentos maternos. Por outro lado, há que considerar que o atendimento à criança, por ter sido direto, mais freqüente e de maior duração que o atendimento à mãe, tem maior chance de afetar o desempenho e o comportamento da primeira. Essa discussão, no entanto, se faz todo sentido em relação aos objetivos específicos do estudo, perde significado no contexto do atendimento clínico. A importância da família em todo processo de apoio psicológico ou psicopedagógico ao escolar não pode ser subestimada.

Com as limitações mencionadas, a realização da pesquisa no contexto de uma instituição de saúde apresentou uma contribuição positiva, no fato de ter demonstrado a adequação do tratamento em uma situação clínica real, beneficiando meninos, que constituem a parcela mais significativa da demanda por atendimento em razão de queixas escolares (Barbosa \& Silvares, 1994), com impacto positivo nos problemas mais comuns encontrados na clientela antes da intervenção.

Os efeitos encontrados são coerentes com os objetivos da proposta de atendimento, circunscrevendo-se às questões escolares.

Enquanto experiência de aprendizagem mediada, as oficinas de linguagem parecem promover modificabilidade cognitiva, ao desenvolver na criança uma genuína disponibilidade para aprender (Goulart, Guhur, \& Mori, 2001). Para as crianças que estão vivendo um momento crítico frente à ameaça de insucesso na tarefa evolutiva da produtividade, o programa constitui fonte de suporte para o enfrentamento da crise, contribuindo para alívio do stress e ativando seus recursos internos para lidar com os desafios da aprendizagem (Linhares, 1998). Seria interessante verificar o grau em que a redução dos sintomas de tensão psicológica se associa à melhora na percepção de si como aprendiz, já que uma das metas das oficinas de linguagem é trabalhar este aspecto, bastante prejudicado nas crianças com queixas escolares (Jacob, 2001).
São necessários estudos de seguimento para investigar o grau de permanência dos ganhos obtidos, bem como investigações sobre o processo da intervenção para elucidar os mecanismos que contribuem efetivamente para as melhoras obtidas.

\section{Referências}

Achenbach, T. M. (1991). Manual for the child behavior checklist / 4-18 and 1991 profile. Burlington: University of Vermont, Department of Psychiatry.

Angelini, A. L., Alves, I. C. C., Custódio, E. M., \& Duarte, W. S. (1997). Manual Matrizes Progressivas Coloridas - Escala Especial de J. C. Raven, Dr. John Raven e Dr. J. H. Court . Padronização Brasileira. São Paulo: Casa do Psicólogo.

Barbosa, J. J., \& Silvares, E. F. (1994). Uma caracterização preliminar das clínicas-escola de Fortaleza. Estudos de Psicologia (Campinas), 11, 50-56.

Bordin, I. A. S., Mari, J. J., \& Caeiro, M. F. (1995). Validação da versão brasileira do "Child Behavior Checklist" (CBCL) - Inventário de comportamentos da infância e adolescência: dados preliminares. Revista ABP-APAL, $17,55-66$.

Campos, M. A. S., \& Marturano, E. M. (2003) Competência interpessoal, problemas escolares e a transição da meninice à adolescência. PaidéiaCadernos de Psicologia e Educação, 13, 73-84.

Clay, M. M. (1993). Reading recovery: a guidebook for teachers in training. Auckland: Heinemann.

Elias, L. C. S. (2002). Solução de problemas interpessoais em crianças com baixo rendimento escolar. Manuscrito não-publicado, Universidade de São Paulo, Ribeirão Preto.

Erikson, E. (1971). Infância e sociedade (G. Amado, Trad.). Rio de Janeiro: Zahar.

Fonseca, V. (1995). Introdução às dificuldades de aprendizagem ( $2^{\underline{a}}$ ed.). Porto Alegre: Artes Médicas.

Goulart, A. M. P. L., Guhur, M. L. P., \& Mori, N. N. R. (2001). Mediação em Feuerstein: alguns elementos para a compreensão das diferenças individuais. Teoria e Prática da Educação, 2, 93-103.

Graminha, S. S. V. (1998). Recursos metodológicos para pesquisas sobre riscos e problemas emocionais e comportamentais na infância. In G. Romanelli \& Z. M. M. B. Alves (Orgs.), Diálogos metodológicos sobre prática de pesquisa (pp. 71-86). Ribeirão Preto: Programa de Pós-Graduação em Psicologia.

Graminha, S. S. V., \& Coelho, W. F. (1994). Problemas emocionais / comportamentais em crianças que necessitam ou não de atendimento psicológico ou psiquiátrico [Resumo]. In Sociedade Brasileira de Psicologia (Org.), XXIV Reunião Anual de Psicologia. Resumos (p. 263). Ribeirão Preto: Autor.

Hughes, J. N. (2000). The essential role of theory in the science of treating children: beyond empirically supported treatments. Journal of School Psychology, 38, 301-330.

Jacob, A. V. (1997). Crianças com atraso escolar: avaliação psicológica através do HTP e TPC. Dissertação de Mestrado não-publicada, Universidade de São Paulo, Ribeirão Preto.

Jacob, A. V. (2001). O desempenho escolar e suas relações com autoconceito e auto-eficácia. Tese de Doutorado não-publicada, Universidade de São Paulo, Ribeirão Preto.

Kazdin, A. E. (2000). Understanding change: from description to explanation in child and adolescent psychotherapy research. Journal of School Psychology, 38, 337-347.

Kernberg, P. F., \& Chazan, S. E. (1993). Crianças com transtornos de comportamento: manual de psicoterapia (D. Batista, Trad.). Porto Alegre: Artes Médicas. 
Linhares, M. B. M. (1998). Atendimento psicopedagógico de crianças em serviço especializado de psicologia infantil na área da Saúde - uma perspectiva desenvolvimentista. Psicopedagogia, 17, 30-36.

Lipp, M. N., \& Romano, A. S. P. (1987). O stress infantil. Estudos de Psicologia (Campinas), 4, 43-49.

Marturano, E. M., Loureiro, S. R., Linhares, M. B. M., \& Machado, V. L. S. (1997). A avaliação psicológica pode fornecer indicadores de problemas associados a dificuldades escolares? In E. M. Marturano, S. R. Loureiro, \& A. W. Zuardi (Orgs.), Estudos em Saúde Mental - 1997 (pp. 11-48). Ribeirão Preto: Faculdade de Medicina de Ribeirão Preto, Universidade de São Paulo.
Masten, A. S., \& Coatsworth, J. D. (1998). The development of competence in favorable and unfavorable environments - lessons from research on successful children. American Psychologist, 53, 205-220.

Mentis, M. (1997). Aprendizagem mediada dentro e fora da sala de aula (J. F. Azevedo, Trad.). São Paulo: Instituto Pieron de Psicologia Aplicada.

Santos, M. A. (1990) Caracterização da clientela de uma clínica psicológica da Prefeitura de São Paulo. Arquivos Brasileiros de Psicologia, 42, 79-94.

Stein, L. M. (1994). TDE- Teste de desempenho escolar: manual para aplicação e interpretação. São Paulo: Casa do psicólogo.

${ }^{1}$ Trabalho financiado pela FAPESP (bolsa de doutorado à primeira autora e auxílio a projeto temático à segunda autora) e pelo CNPq (auxílio a projeto de pesquisa).

Luciana Carla dos Santos Elias, psicóloga, é doutora em Psicologia pela Universidade de São Paulo - Ribeirão Preto.

Edna Maria Marturano, doutora em Ciências pela Universidade de São Paulo, é professora titular no Departamento de Neurologia, Psiquiatria e Psicologia Médica da Faculdade de Medicina da Universidade de São Paulo - Ribeirão Preto. Endereço para correspondência: Av. Nove de Julho, 980; Ribeirão Preto, SP; CEP 14025-000. Tel: (16) 625-0309. Fax: (16) 635-0713. E-mail: emmartur@fmrp.usp.br 